\title{
Filosofía y tiempo final
}

Eduardo Subirats Universidad de Nueva York, Estados Unidos de América

Resumen

Revisar el efecto del 11 de septiembre como detonante de una nueva guerra global extendida públicamente a través de los mass media, y analizar las relaciones con el confinamiento individual, la dependencia de los medios electrónicos, el ecocidio sistemático y, principalmente, con la actual crisis del medio intelectual, son puntos centrales de este texto. La afirmación academicista del postestructuralismo, en la que el lenguaje se ostenta como única realidad legitimada, se enfrenta e impone a la creatividad y a la experiencia individual; de ello se desprenden consecuencias morales: nihilismo intelectual, constitución de la realidad como espectáculo, destrucción de culturas humanas con afanes colonialistas y destrucción de la naturaleza apoyada en el dominio científico y el poder tecnoindustrial. En el ensayo se reflexiona sobre la Teoría Crítica después del postmodernismo norteamericano, y sobre la inminencia del tiempo final contrastada con la estupidización masiva. Ante esto se plantea la recuperación de la esperanza como conocimiento activo y transformador; como el Prinzip Hoffnung de Ernst Bloch.

Palabras clave: 11 de septiembre, nihilismo intelectual, tiempo final (Endzeit), Teoría Crítica, Prinzip Hoffnung. 
Abstract

Review the effect of September 11 as a trigger for a new global war extended publicly through the mass media and analyze relationships with individual confinement, the dependence of the electronic media, the systematic ecocide and mainly with the current crisis in the intellectual milieu, are central points of this text. The academic affirmation of post-structuralism, in which the language holds as only legitimate reality, facing and requires creativity and individual experience. This gives rise to moral consequences: intellectual nihilism, construction of the reality show, destruction of human with colonialist cares cultures and destruction of nature supported in the scientific domain and power techno. In the essay he reflects on the critical theory after the American Postmodernism and the imminence of the end time contrasted with the massive estupidización.

Keywords: 11 of september, intellectual nihilism, critical theory, Endzeit, Prinzip Hoffnung

W uestra condición de confinamiento urbanístico y electrónico lado "la existencia sitiada", se me hizo presente días después del ataque al World Trade Center y al Pentágono. Hoy las huellas de aquel escenario han sido cuidadosamente borradas de las memorias colectivas, y suplantadas por el espectáculo de la guerra global y la configuración de un renovado sistema de dominación planetaria. Por eso quiero relatarles algunos detalles de aquella situación inaugural. A los ataques jihadistas le siguió una serie de agresiones a oficinas públicas, así como a individuos, con esporas letales de la bacteria Ánthrax a través de cartas de origen desconocido. Durante varios días, los mass media sembraron sistemáticamente el pánico sobre una aterrada masa mediática. 
Las esporas, lo mismo que los terroristas, se configuraron performáticamente como un virtual peligro letal que podía aparecer en cualquier momento y en todas partes: en los transportes públicos, en las aulas de la universidad o en la privacidad doméstica electrónicamente vigilada. Un clima de terror e inseguridad se expandía, en consecuencia, desde los pentágonos del poder de Washington hasta los más remotos confines del mundo. Las víctimas obedecían a un deliberado principio arbitrario: un senador, un empleado de correo, una enfermera. La opacidad mediáticamente construida de sus autores no hacía sino intensificar su efecto intimidador. La información mediática estaba perfectamente uniformada bajo los lenguajes y las realidades prediseñadas por la cúpula militar. La nación entera vivía un estado electrónico de sitio representado como cumplimiento de la libertad. Nunca había imaginado hasta entonces la radical deconstrucción de la vida social y la desintegración de la existencia individual que en los años sesenta barruntábamos bajo el lema de "la sociedad del espectáculo".

No es irrelevante subrayar que esta arma biológica, producida bajo los auspicios del gobierno británico durante la Segunda Guerra Mundial, ya se habían utilizado contra nacionalistas africanos en Rodesia, en lugar de diseminarlos sobre la población civil alemana a la que originalmente estaba destinada. La propaganda gubernamental identificó de todos modos estas bacterias con un aleatorio bioterrorismo, y las asoció con el gobierno de Sadam Hussein. Y cuando unas semanas más tarde se supo ocasionalmente que sólo la industria militar de los Estados Unidos podían producir esporas de tan sofistica calidad como las que se habían usado los días que siguieron a aquel 11 de septiembre, ya era demasiado tarde. La guerra global había sido proclamada. El éxtasis nacionalista y el fuego belicista incendiaron en cuestión de horas a todo el país. Una nueva era había comenzado. ${ }^{1}$

\footnotetext{
${ }^{1}$ En el proceso judicial postmortem en el que se reveló el presunto actor de aquellos
} 
Tres momentos definían este generalizado estado de sitio. Primero, el confinamiento social bajo el principio del terror mediático y militar. Segundo, la dependencia individual y colectiva de esos mismos medios electrónicos de comunicación como sistema de realidad. Tercero, la impotencia humana frente a discursos políticos ostensiblemente fraudulentos y a decisiones militares de consecuencias manifiestamente genocidas. Ésta es la constelación histórica que he analizado en La existencia sitiada $(2006,2007)$.

En los ensayos deliberadamente fracturados que componen $L a$ existencia sitiada he tratado de definir conceptual y expresivamente una condición humana terminal en una edad caracterizada por el diseño industrial de la realidad a escala global, el escarnio mediático universal de la masa electrónica, un estado de guerra indefinida y la destrucción del ecosistema. Pero no es éste sólo mi punto de partida. En mis años en la academia norteamericana he experimentado en mi propia piel otro aspecto de nuestra constelación histórica negativa: el confinamiento intelectual, la compartimentación y la subsiguiente desarticulación de la posibilidad misma de pensamiento. El estructuralismo y postestructuralismo pueden celebrarse como la expresión y legitimación formales de este estado de sitio intelectual. Su postulado universal de que nada existe fuera del lenguaje y sólo la intertextualidad es real traduce la voluntad administrativa de confinar microsaberes, controlarlos lingüísticamente y ponerlos institucionalmente fuera del alcance de su reflexión. La construcción de realidades ficticias es su consecuencia. Su implícita condena de la experiencia individual y de la creativi-

atentados, un ingeniero militar que presuntamente cometió suicidio, el fiscal señaló de todos modos: "We regret that we will not have the opportunity to present evidence to the jury". 
dad como un absurdo, desde el punto de vista de la racionalidad profesional, pone de manifiesto su rostro dogmático. Y en la misma medida en que se confina el ser en el interior del lenguaje, la administración de éste se eleva a principio de todo poder, en las jergas del espectáculo postpolítico lo mismo que en los discursos postintelectuales de un cerrado academicismo. Lo que no se subsuma a un terminante control lingüístico, sean disidencias, sean poemas, adquiere por su propia naturaleza extralingüística el carácter existencial de un fantasma, el significado burocrático de la herejía y el valor ontológico de una nada. La consecuencia moral de este deconstruccionismo institucional es el hibridismo de imbecilidad y cinismo que hoy rige nuestros destinos.

Bajo cuatro aspectos he tratado de analizar esta condición terminal de nuestra existencia. El primero es la constitución de la realidad como espectáculo. Bajo este concepto de "espectáculo" describo nuestras vidas, reducidas a la soledad y a la impotencia, en medio de una realidad producida, empaquetada y difundida por las industrias culturales como un hecho cumplido e inapelable, ya se trate de la felicidad de la Coca-Cola, o de la seguridad que proporciona la acumulación indefinida de misiles con cabezas nucleares.

Mi segundo análisis plantea el vasto dilema de una destrucción de cultos y culturas humanas que no ha cesado de extenderse desde los días fundacionales del colonialismo moderno. Una destrucción cuyos momentos constituyentes hay que buscarlos en los pioneros de la teología política del apóstol Paulo y de la epistemología moderna de Francis Bacon. Una destrucción de culturas que en el momento actual posee dimensiones colosales.

El tercer dilema que planteo es el sentido unívocamente destructivo que ha asumido la dominación científica de la naturaleza. El Manhattan Project, bajo cuyos auspicios se cumplió el holocausto nuclear de Hiroshima y Nagasaki, es el paradigma de esta ciencia destructiva. Las tecnologías de destrucción nuclear, de 
colonización biológica y el calentamiento global son sus síntomas más ostensibles.

Espectáculo, regresión cultural y biológica, y poder tecnoindustrial son fuerzas que confluyen y concluyen en lo que constituye el momento central de la crisis civilizatoria y existencial de nuestro tiempo: la inversión del orden a la vez temporal y metafísico del progreso. En su versión escatológica, este ideal de progreso se definía como un proceso indefinido de cumplimiento del ser en el límite de un tiempo final, es decir, lo que el apóstol Juan definió programáticamente como "revelación" o "apocalipsis". Su expresión secularizada en las filosofías del progreso ligadas a la revolución industrial ha trocado hoy su bandera del mañana mejor por la administración de crisis sociales, conflictos militares y desastres ecológicos. Su expresión cultural global es la ritualización académica del final de la filosofía y del arte, la muerte del hombre y la desaparición del intelectual.

Existencia sitiada y conciencia sitiada apuntan hacia esta situación existencial e histórica terminal. Exponen un presente senalado por el vacío y el no ser, por el nihilismo como su expresión filosófica, y un deseo generalizado de destrucción que se expresa con la misma violencia en la agresividad ecocida del consumo energético, como en las estrategias y tecnologías letales de la guerra global que lo sustentan. Bajo el signo y el sino de nuestra existencia sitiada se ha congelado el tiempo histórico. La volatilización mediática de lo real y la liquidación institucional del intelectual son sus condiciones absolutas. Su bandera victoriosa: la extensión ilimitada de la violencia y el poder absoluto del espectáculo.

3

Una de las situaciones chuscas que me llamaron la atención apenas un par de meses después del ataque al World Trade Center, 
y cuando la efervescencia y propaganda belicista era más intensa, fue un panel en la New School de New York en la cual las cabezas visibles del postmodern norteamericano celebraron el final de la teoría crítica. Fue en realidad la última aparición pública del postmodernismo, su acto o acta de defunción. Sin embargo, es cierto que la "teoría crítica" se había reducido a los límites institucionales de una escuela, al contexto histórico de los fascismos europeos del siglo pasado y a las obras de un puñado de filósofos alemanes. Pero en su ensayo programático de 1937, en el que establecía la distinción entre teoría tradicional y teoría crítica, Max Horkheimer no definía a esta última como una escuela, ni tampoco como un pensamiento ligado a una coyuntura política específica. Mucho menos aún la institucionalizaba como un método. Horkheimer ponía en cuestión, más bien, la cosificación de una categoría ideológica de ciencia y de teoría, en el sentido en que ayer lo asumía la sociología del conocimiento y hoy lo asumen los cultural studies. Su proyecto de una teoría crítica surgía a partir de una reflexión filosófica y sociológica sobre los sistemas totalitarios de control humano, el empobrecimiento emocional e intelectual de la cultura industrial y sus reiteradas crisis económicas y militares. La teoría crítica era la respuesta a la sucesión de regímenes totalitarios, genocidios y procesos de destrucción social que ha acompañado a la acumulación de riqueza, al desarrollo tecnológico y a los sistemas crecientemente perfeccionados de control social. Asimismo, esta teoría se concebía como heredera de las ilustraciones europeas, de Montaigne a Marx (Horkheimer, 1868, t. I: 156 y ss.).

No obstante, esta teoría crítica, si queremos conservar un nombre que la cultura industrial y académica ha trivializado, debe definirse de nuevo. Y debe hacerse bajo una perspectiva más radical y elemental de la que pudiera concebirse en la Europa de los fascismos pasados. Esta crítica se configura, en primer lugar, como 
reflexión del logos de la civilización sobre sus últimas consecuencias destructivas. Pero no se trata solamente de una crítica de la razón instrumental. Tampoco de la reconstrucción de los límites o de la "dialéctica" de la ilustración. Reflexión sobre el logos significa la reconstrucción crítica de sus constituyentes. Significa su esclarecimiento genealógico. Comprende la revisión de los orígenes religiosos y mitológicos de este logos occidental. Debe plantear los límites de su secularización bajo las epistemologías científicas. Ha de redefinir el significado de totalitarismo en la edad de la guerra nuclear y del espectáculo.

Sabemos qué caminos del pensamiento conducen a ninguna parte: la cantonalización académica de conocimientos, las vigiladas micropolíticas, los valores de la cultura espectacular, la tecnociencia instrumental, el positivismo estructuralista como su legitimación escritural. La crítica filosófica de nuestro tiempo final, la teoría crítica, la reflexión intelectual y artística de nuestro presente tiene que explorar, restaurar y reformular, en primer lugar, la tradición espiritual que le ha sido arrebatada. Tiene que hacerlo para construir su horizonte histórico y sus categorías analíticas. Tiene que hacerlo también a partir de las experiencias tanto de las metrópolis imperiales y coloniales, como de las voces intelectuales y proyectos civilizatorios que aquéllas han amordazado y destruido a lo largo del proceso de su expansión colonial en el llamado "Tercer Mundo".

4

A nuestra edad política y espiritualmente congelada bajo los signos del poder global que en 1945 se instauró sobre las cenizas del Ground Zero de Hiroshima y Nagasaki, Günther Anders la definió como "Tiempo Final" (Endzeit). Sus características se pueden poner al día bajo una serie de categorías elementales: amenaza universal de extinción biológica a través de la acción combinada de la 
acumulación de residuos nucleares, el incremento de la producción industrial de factores biocidas, el calentamiento atmosférico y la destrucción industrial de los sistemas ecológicos más fundamentales para la supervivencia del planeta, como el Amazonas o los círculos polares. Cierra este paisaje un incremento de la violencia global alimentada por una omnipotente industria militar. Pero Anders ya añadió a este cuadro histórico actual otro aspecto: Apokalypse-Blindheit - la ceguera frente al ocaso de la humanidad, frente a la destrucción, frente a los genocidios de hoy, frente al Apocalipsis- El significado de esta ceguera a la situación histórica de un tiempo final puede resumirse con una regla de oro: la mutilación intelectual, la parálisis imaginativa, la suspensión universal de la inteligencia, el entorpecimiento generalizado de la sensibilidad artística — desde las aulas universitarias y los museos, hasta las cadenas de televisión-. Bajo su imperativo se expande la estupidización masiva frente al desastre mundial que nos rodea (Anders, 1972: 106 y ss.).

"Furcht in der Hoffnung, Hoffnung in der Furcht": temor en la esperanza y esperanza en medio del "temor y temblor"-bajo esta unidad, ligada a la figura espiritual de Job_-, formulaba Ernst Bloch el sentido histórico y metafísico de este Prinzip Hoffnung en el mundo de hoy. Esta esperanza ya no es la espera expectativa de algo mejor o simplemente menos malo. Bloch lo definió a partir de una historia y una tradición colectivas que incluyen pueblos y tradiciones espirituales, así como formas de resistencia democrática. Una tradición que comprende a místicos islámicos, herejes cristianos, cabalistas y líderes revolucionarios. Esta comunidad histórica del verdadero espíritu, que debe distinguirse rotundamente del espíritu de la ekklesia y sus subproductos secularizados, no se funda en un sentido "interior" de fe, ni en la subsiguiente esperanza de la expectativa expectante formulada por la teología política de Paulo. Su punto de partida no es tampoco la famosa conciencia 
infinita de Luther y Hegel, es la historia de las luchas y rebeliones de los pueblos por preservar su soberanía frente a la destrucción, al genocidio y a los poderes tiránicos, a los quilombos de los esclavos coloniales de América y a la rebelión de Kronstadt, Thomas Münzer o Rosa Luxemburg (Bloch, 1959, vol. I: 171, 185, 311 y ss.).

Esta esperanza no es un estado pseudomístico de contemplación apática, ni asume las funciones consolatorias que la spes cristiana ha desempeñado a lo largo de su historia. Por el contrario, es un conocimiento activo y trasformador de la realidad en el sentido de la praxis de Kant o de Marx. Está indisolublemente ligada a la crítica de los sistemas de destrucción social y a la solidaridad con toda la humanidad. Es un principio intelectual y espiritual constituyente de aquel pensamiento que tenga el valor y la voluntad de poner de manifiesto los conflictos, las amenazas y las falsedades que acosan la existencia humana bajo el logos mediáticamente naturalizado de una catástrofe mundial.

\section{Bibliografía}

Anders, Günther, 1972, Endzeit und Zeitende, München, C. H. Beck. Bloch, Günther, 1959, Das Prinzip Hoffnung, vol. I, Suhrkamp Verlag, Frankfurt a. M.

Horkheimer, Max, 1968, Kritische Theorie, t. I (ed. Alfred Schmidt), Frankfurt a.M., S. Fischer Verlag.

Subirats, Eduardo, 2006, La existencia sitiada, Fineo, México-Monterrey. 